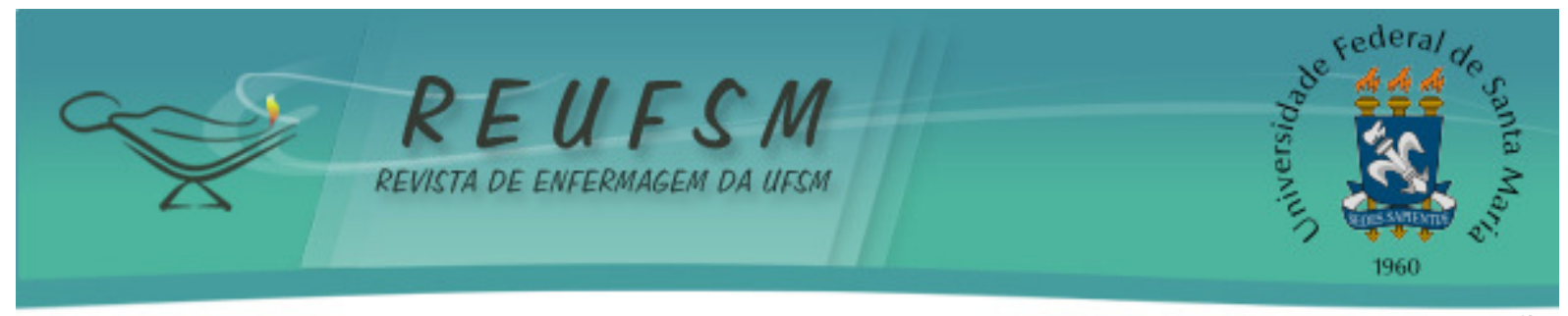

ARTIGO DE REVISÃO

\title{
PRODUÇÃO CIENTÍFICA DO ENFERMEIRO GESTOR: ESTUDO BIBLIOMÉTRICO EM PERIÓDICOS QUALIS A2 E B1
}

\section{SCIENTIFIC PRODUCTION OF THE NURSE MANAGER: BIBLIOMETRIC STUDY OF JOURNALS QUALIS A2 E B1}

\section{LA PRODUCCIÓN CIENTÍFICA DEL ENFERMERO GESTOR: ESTUDIO BIBLIOMÉTRICO EN REVISTAS QUALIS A2 Y B1}

\author{
Ricardo Quintão Vieira ${ }^{1}$ \\ Maria Cristina Sanna ${ }^{2}$
}

RESUMO: Objetivo: identificar, descrever e analisar a produção científica realizada por enfermeiros gestores, de 2005 a 2011, em periódicos científicos brasileiros Qualis A2 e B1, um sistema brasileiro de classificação utilizado pela Coordenação de Aperfeiçoamento de Pessoal de Nível Superior para avaliar os programas de pós-graduação. Método: estudo bibliométrico focado em variáveis de procedência, cargo profissional, instituição, ano de publicação da obra, titulação acadêmica, população e descritores. Resultados: a maioria dos enfermeiros gestores e os locais de estudo pertenciam à região Sudeste, com título de mestre, e a população de estudo foi constituída de pacientes e familiares. A análise dos termos de descrição do objeto de estudo não identificou tendência temática, pois eram variados. O foco administrativo indicou tendência para a prática de gerenciamento de recursos humanos. Conclusão: os estudos mostraram que os enfermeiros gestores estão mais interessados em temas voltados à assistência ao paciente.

Descritores: Enfermagem; Pesquisa em administração de enfermagem; Organização e administração; Indicadores de produção científica; Bibliometria.

ABSTRACT: Objective: to identify, describe and analyze the scientific production performed by nurse managers, 2005 to 2011, in Brazilian scientific journals Qualis A2 and B1, a Brazilian system of classification used by "Coordenação de Aperfeiçoamento de Pessoal de Nível Superior" for evaluation the postgraduate programs. Method: bibliometric study focused on the position of the author, institution, year of publication of a work, academic rank, population and descriptors. Results: showed that the majority of nurse managers or their studies belonged to the Southeast, had master's degrees with study population consisted of patients and relatives. The analysis of the terms did not identify thematic trends of study, they were varied. There was a trend to practice human resources management. Conclusion: nurse managers are more interested in topics related to patient care.

Descriptors: Nursing; Nursing administration research; Organization and administration; Scientific publication indicators; Bibliometrics.

RESUMEN: Objetivo: identificar, describir y analizar la producción científica realizada por los enfermeras gestores, 2005-2011, en revistas científicas brasileñas Qualis A2 y B1, un sistema de clasificación utilizado por la Coordinación de Perfeccionamiento de Personal

\footnotetext{
${ }^{1}$ Graduado em Biblioteconomia pela Universidade de São Paulo (USP) e Enfermagem Universidade Nove de Julho (UNINOVE). Bibliotecário do Senac SP. Mestrando em Ciências da Saúde pela Escola Paulista de Enfermagem (EPE) da Universidade Federal de São Paulo (UNIFESP). Membro do Grupo de Estudos e Pesquisa em Administração em Saúde e Gerenciamento em Enfermagem (GEPAG). São Paulo, SP, Brasil. E-mail: ricqv@ig.com.br

${ }^{2}$ Enfermeira. Doutora em Enfermagem pela USP, Pós-Doutorado em História da Enfermagem pela Escola de Enfermagem Anna Nery da Universidade Federal do Rio de Janeiro. Pesquisadora Independente. Orientadora Credenciada junto à Pósgraduação senso estrito da UNIFESP. Pesquisadora do GEPAG. São Paulo, SP, Brasil. E-mail: mcsanna@uol.com.br
} 


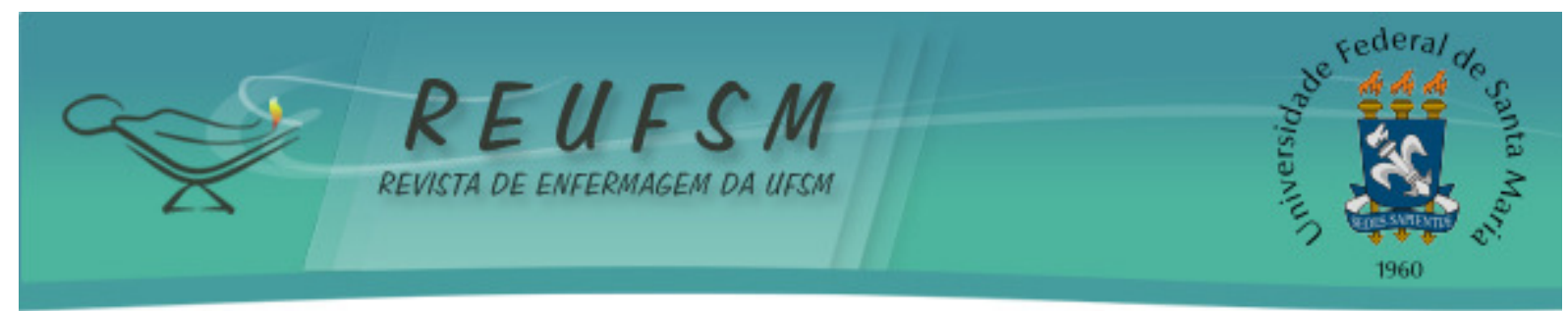

de Nivel Superior para evaluar los programas de posgrado. Método: estudio bibliométrico centrado en las variables de origen, posición profesional, institución, año de la publicación de la obra, grados académicos, la población y descriptores. Resultados: la mayoría de los enfermeros gestores y los estudios pertenecían al Sureste, con título de maestría, y la población de estudio fue constituida por pacientes y familiares. El análisis de los términos de descripción del objeto de estudio no identificó tendencia temática, pues eran variadas. El enfoque administrativo indicó tendencia para la práctica de la gestión de recursos humanos. Conclusión: los enfermeros gestores están más interesados en temas relacionados con la atención al paciente.

Descriptores: Enfermería; Investigación en administración de enfermería; Organización y administración; Indicadores de producción científica; Bibliometría.

\section{INTRODUÇÃO}

A atualização do gestor de enfermagem é um dos requisitos para a manutenção da qualidade de assistência ao paciente e é necessária para o enfrentamento das mudanças que ocorrem nos ambientes corporativos públicos e privados de saúde. Além do comportamento de pesquisar e consumir informação objetivando a atualização profissional, o enfermeiro pode assumir o posicionamento de contribuir com seus próprios estudos sobre a prática administrativa, por meio da publicação de relatos de suas experiências e de resultados das pesquisas que realiza.

0 enfermeiro com dupla função - de pesquisador e gestor, necessita conciliar a investigação científica com a prática diária em seu ambiente de trabalho e esse esforço tem sido relatado na literatura científica, com descrição de formas administrativas de condução de serviços brasileiros de enfermagem, desde o planejamento direto de cuidado ao paciente às decisões estratégicas institucionais que afetam outras esferas de chefia. ${ }^{1}$

Para compartilhar essas informações, existem diversos canais de divulgação de informações científicas, tais como trabalhos apresentados em eventos, artigos publicados em periódicos científicos e produtos de pesquisas acadêmicas disponibilizados na forma de teses, dissertações e monografias. A análise desses canais pode fornecer informações sobre o comportamento dos gestores que também desempenham a função de produtores de conhecimento.

Sabe-se que, do período de 1960 a 1985, os enfermeiros docentes publicaram mais trabalhos científicos em periódicos que os enfermeiros assistenciais. ${ }^{2}$ Além disso, a maior parte dos enfermeiros assistenciais que publicaram (45,76\%) desenvolveu dupla atividade assistencial e administrativa. Esse comportamento expôs a dicotomia do fazer pesquisa da Enfermagem brasileira: de um lado aquela realizada pelos enfermeiros docentes, com a produção acadêmica e, por outro, a de autoria de enfermeiros assistenciais, com produtos que versam sobre sua prática diária em ambientes de trabalho. Acrescente-se que esse mesmo estudo constatou que 33\% do total de enfermeiros assistenciais autores analisados possuíam também encargos administrativos. ${ }^{2}$

O quadro começou a mudar a partir da inserção do enfermeiro assistencial nas pesquisas sobre Administração da Enfermagem, sendo um de seus indícios, o aumento de trabalhos acadêmicos sobre essa temática vinculados à pós-graduação senso estrito, produzidos nas décadas de 1980 e $1990 .^{3-4}$

Até o momento, muitos trabalhos sobre o tema investigaram a produção sobre Administração em Enfermagem, e poucos analisaram a inserção do enfermeiro líder na academia, seja pela ótica histórica ou bibliométrica, desconhecendo-se quais seus objetos de pesquisa, qual sua posição hierárquica numa equipe de pesquisa e seus locais de atuação. ${ }^{5}$ Há, portanto, uma lacuna na literatura científica no que se refere ao 


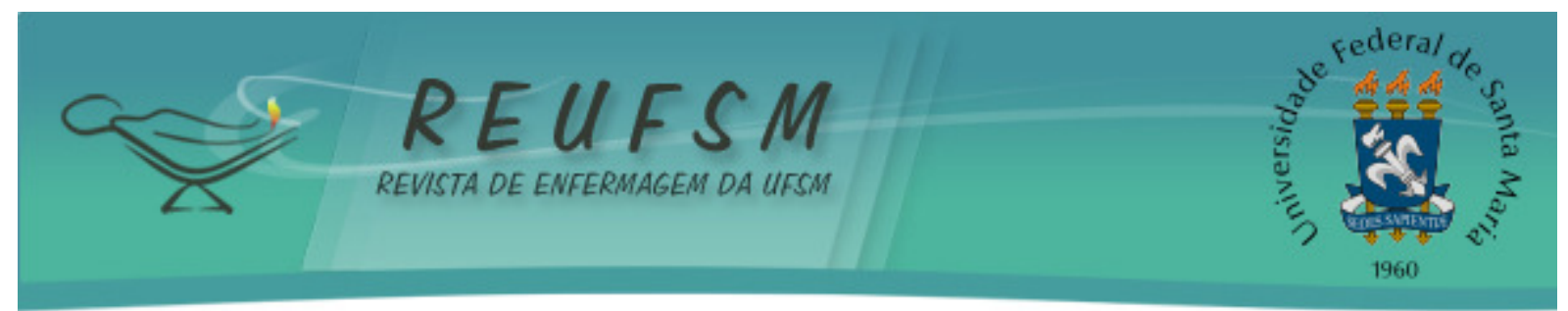

conhecimento sobre o esforço desse sujeito pesquisador, que tem o poder de tomar decisões e aplicar pesquisas sobre Administração em Enfermagem.

Desse modo, justifica-se a realização do presente estudo, pela necessidade de se contribuir para o desenho do perfil científico do enfermeiro gestor, aqui definido como membro da equipe de enfermagem ou equipe multiprofissional de saúde, responsável pelas tomadas de decisões fundamentais no processo de trabalho gerencial em enfermagem. Para isso, buscou-se o recurso bibliométrico, cuja abordagem tem o potencial de fornecer indícios a pesquisadores, seja em universidades, na forma de grupos de pesquisa, seja na gestão de políticas científicas em âmbitos econômico, social e educacional, ou, ainda, na alocação de recursos financeiros e de tempo, dentre outros. ${ }^{6}$

Assim, o objetivo do presente estudo é identificar, descrever e analisar a produção científica realizada por enfermeiros gestores, de 2005 a 2011, em periódicos científicos brasileiros Qualis A2 e B1, um sistema brasileiro de classificação de periódicos utilizado pela Coordenação de Aperfeiçoamento de Pessoal de Nível Superior para avaliar os programas de pós-graduação.

\section{MÉTODO}

Estudo bibliométrico realizado em revistas científicas brasileiras de Enfermagem conceituadas pela Coordenação de Aperfeiçoamento de Pessoal de Nível Superior (CAPES), nos estratos A2 e B1, para a área da Enfermagem, segundo o critério Qualis de $2010 .{ }^{7}$ Esse critério apresenta uma escala de avaliação aplicada a periódicos científicos, que vai de $A 1$ (peso elevado) e percorre os índices A2, B1, B2, B3, B4, B5 até chegar C (peso zero).

Foram considerados os seguintes periódicos, conforme o critério Qualis 2010, A2: Acta Paulista de Enfermagem, Revista da Escola de Enfermagem da Universidade de São Paulo (USP), Revista Latino-Americana de Enfermagem e Texto \& Contexto Enfermagem. Além delas, foram acessadas as revistas Qualis B1: Escola Anna Nery Revista de Enfermagem, Revista Brasileira de Enfermagem, Revista Enfermagem da Universidade Federal do Rio de Janeiro (UERJ), Online Brazilian Journal of Nursing e Revista Gaúcha de Enfermagem.

A busca em bases de dados foi realizada no período de outubro de 2010 a julho de 2012. Preferiu-se fazer um recorte temporal de 2005 a 2011 a outro estudo longitudinal mais amplo, a fim de diluir dados de representação de assuntos desenvolvidos mais recentemente por enfermeiros gestores. Essa escolha ocorreu devido à rapidez observada na mudança organizacional e seu impacto sobre as pessoas e na cultura das instituições de saúde, que afeta diretamente os gerentes. ${ }^{8}$

A partir das informações presentes nos dados de identificação dos próprios artigos, se criou três critérios de seleção. 0 primeiro, que houvesse indicação do autor ser enfermeiro gerente, administrador ou gestor de departamento, divisão, serviço, seção ou setor. 0 segundo critério foi sua vinculação a instituições de assistência à saúde tais como: hospitais, clínicas, laboratórios, postos de saúde e similares. O terceiro critério de inclusão foi o formato do trabalho, que deveria conter o texto completo e estar escrito em língua portuguesa.

Foram excluídas as seções de errata, carta ao editor e entrevistas. Além disso, não foram considerados textos de autoria de enfermeiros supervisores ou coordenadores de cursos de formação profissional, líderes de grupos de pesquisa acadêmica e diretores de setor de educação permanente de instituições de ensino.

0 estudo bibliométrico utiliza variáveis de análise quantitativa a partir de fontes de informação registradas em documentos tais como: livros, artigos de periódicos, teses e dissertações. Historicamente, os bibliotecários apontavam como variáveis bibliométricas o número de empréstimos (circulação) e de citações, além da frequência de extensão de frases. ${ }^{9}$ Investigando os estudos bibliométricos realizados por enfermeiros, é possível 


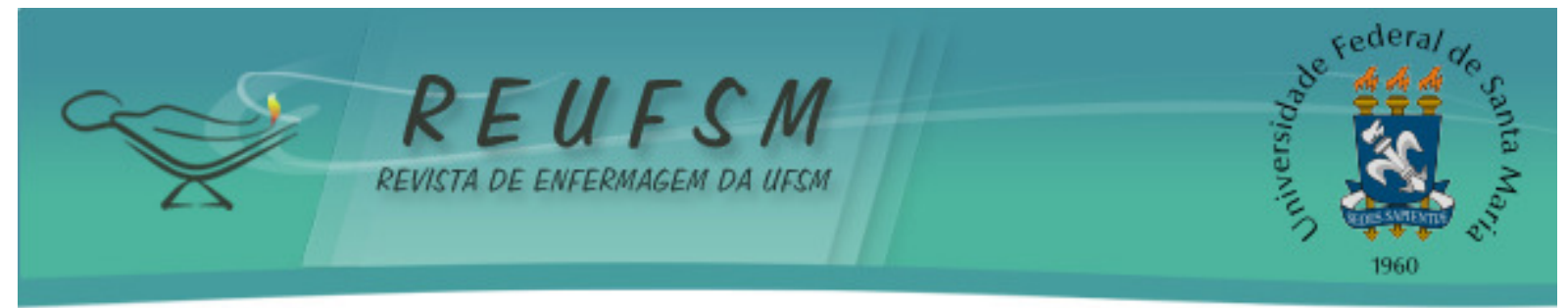

reconhecer que seu foco se dirige para variáveis de pesquisa como número de citações em bases de dados, área do conhecimento, autor, instituição, tipo de documento, título de periódico, ano de publicação ou defesa, local, idioma, método de pesquisa e descritor. ${ }^{10-13}$

Para o presente estudo, foram utilizadas as seguintes variáveis: posicionamento hierárquico do autor em relação ao grupo de pesquisa do artigo, cargo e tipo de instituição em que trabalha, ano de publicação do artigo e titulação acadêmica no momento da publicação - em sua falta, foi consultado o currículo disponibilizado na Plataforma Lattes do Conselho Nacional de Desenvolvimento Científico e Tecnológico (CNPq). Também foram anotadas a população do estudo e as palavras-chave atribuídas, pelos autores, para indexação dos textos em bases de dados bibliográficas. Para isso, foi criado um banco de dados sob a forma de planilha eletrônica, onde foram dispostas as informações correspondentes às variáveis do estudo e também inseridos os arquivos eletrônicos dos artigos selecionados e capturados, para facilitar a conferência dos dados.

Os dados foram analisados por meio do cálculo das frequências absoluta e relativa, com abordagem bibliométrica dos assuntos tratados nos artigos. Foi necessário fornecer bases terminológicas de indexação das palavras-chave atribuídas pelos autores, a fim de diminuir dissonâncias semânticas. Com essa finalidade, foram utilizados dois instrumentos de estruturação do conhecimento. O primeiro foi o Tesauro do Ministério da Saúde, um vocabulário que permite indexar descritores não controlados em termos controlados, que serviram de base para a análise métrica de conteúdo temático dos trabalhos. ${ }^{14} \mathrm{~A}$ seguir, os termos foram organizados em classes de assuntos, com utilização do segundo instrumento de estruturação da informação sobre Administração em Enfermagem. ${ }^{15}$

\section{RESULTADOS E DISCUSSÃO}

As oito revistas científicas em que se realizou a coleta de dados apresentaram o total de 243 artigos, distribuídos na Tabela 1, conforme o título do periódico.

Tabela 1 - Distribuição de artigos em periódicos Qualis A2 e B1, conforme a produção do enfermeiro gestor, 2005-2010.

\begin{tabular}{lccr}
\hline \multicolumn{1}{c}{ Título do Periódico } & QUALIS & N. & $\%$ \\
\hline Revista da Escola de Enfermagem da USP & A2 & 49 & 20,2 \\
Revista Gaúcha de Enfermagem & B1 & 39 & 16,0 \\
Revista Brasileira de Enfermagem & B1 & 26 & 10,7 \\
Revista de Enfermagem da UERJ & B1 & 26 & 10,7 \\
Texto \& Contexto - Enfermagem & B1 & 25 & 10,3 \\
Revista de Enfermagem - Escola Anna Nery & B1 & 25 & 10,3 \\
Acta Paulista de Enfermagem & A2 & 23 & 9,5 \\
Revista Latino-Americana de Enfermagem & A2 & 18 & 7,4 \\
Online Brazilian Journal of Nursing & B1 & 12 & 4,9 \\
\hline Total & & 243 & 100,0 \\
\hline
\end{tabular}

O quantitativo de artigos por revista oscilou entre 18 e 10, considerando-se essa distribuição equilibrada, visto que não há, no Brasil, periódicos científicos voltados exclusivamente para a temática Administração em Enfermagem.

Acrescente-se ainda que a concentração maior de artigos na Revista da Escola de Enfermagem da USP, Revista Brasileira de Enfermagem e Revista Gaúcha de Enfermagem, 


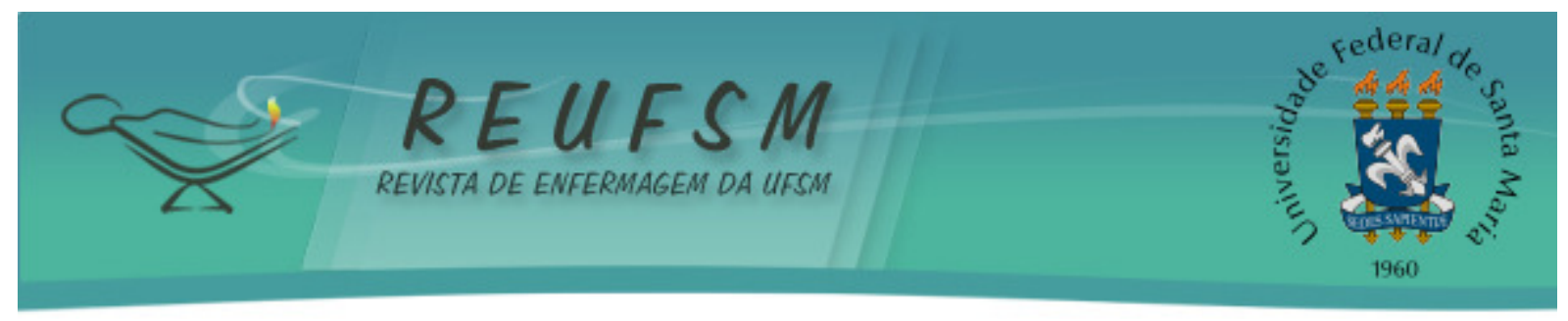

ainda que discreta, pode ser explicada pelo fato da primeira e terceira serem vinculadas a instituições de ensino e pesquisa com tradição na produção sobre esse conteúdo e pelo fato da segunda ser o órgão oficial de comunicação da entidade de classe mais representativa politicamente no país, o que guarda estreita vinculação com a prática gerencial.

Em relação ao número de revistas científicas, conforme sua classificação Qualis, houve equilíbrio na distribuição da produção científica, sendo 115 (47\%) em periódicos Qualis A2 e 128 (53\%) em B1.

Houve também equilíbrio entre os anos de publicação, sendo 2005 com 37(15\%), 2006 com 39(16\%), 2007 com 35(14\%), 2008 com 21(9\%), 2009 com 39(16\%), 2010 com $33(14 \%)$ e 2011 com 39(16\%).

Foram identificados 211 diferentes autores enfermeiros gestores, sendo que 82 $(28,8 \%)$ se autodenominaram "chefe"; 76 (26,7\%) “coordenador”; 44 (15,4\%) “diretor"; 27 $(9,5 \%)$ "gerente" e $19(6,7 \%)$ "supervisor". O restante, totalizando $37(12,9 \%)$ autores, utilizou outras denominações tais como, "responsável", "encarregado", "presidente", "líder", "corresponsável", "executivo", "vice-coordenador", "gestor" e "vice-diretor". Associados a esses cargos, a maioria dos autores citaram os setores por eles responsáveis, totalizando 60 setores diferentes com 178 citações. Os mais frequentes foram "Clínica Cirúrgica", com 18 (10,1\%) citações; "Unidade de Terapia Intensiva" com 16 (9\%); "Clínica Médica" e "Pediatria" com $10(5,6 \%)$ cada; "Centro Obstétrico" com nove (5,1\%); "Ambulatório" com oito (4,5\%); "Emergência" e "Centro Cirúrgico" com seis $(3,4 \%)$ cada; "Neonatal" e "Programa de Saúde da Família" com cinco $(2,8 \%)$ cada. 0 restante das 50 citações equivaleu a $47,8 \%$ do total de locais e corresponderam a outros setores de serviços de saúde.

A análise do tipo de instituição de trabalho dos autores revelou que 223 deles $(91,8 \%)$ ocupavam postos de trabalho em hospitais, seguidos pelo Programa de Saúde da Família (3,5\%). Foram citados outros 18 tipos de instituições diferentes, mas pouco frequentes. É interessante observar que a maior parte da produção científica nesse campo do conhecimento esteja vinculada ao ambiente hospitalar. Talvez porque a Enfermagem Profissional tenha sido construída principalmente a partir da organização do hospital moderno e a tradição de pesquisa acabe por se concentrar nesse ambiente. Outra possibilidade desse comportamento seja a preferência dos enfermeiros gestores de instituições de saúde da Atenção Básica pelos periódicos de Saúde Pública ou Saúde Coletiva, que são canais específicos e interdisciplinares de comunicação científica. Se isso está ocorrendo de fato, surgem novos potenciais de investigações bibliométricas que podem ser realizadas a partir desses veículos.

A análise da distribuição dos autores, por região geográfica de procedência, destacou São Paulo como o estado de mais frequente citação, com 136 autores $(47,7 \%)$; seguido pelo Rio de Janeiro, 41 (14,4\%); Rio Grande do Sul, 38 (13,3\%); e Santa Catarina e Paraná, 18 (6,3\%) cada. $O$ restante dos estados totalizou 34 pessoas $(11,9 \%)$. A região Sudeste apresentou 188 autores (66\%), enquanto a Região Sul 74 (26\%); a Região Nordeste $18(6,3 \%)$, a Região CentroOeste quatro $(1,4 \%)$ e a Região Norte um $(0,4 \%)$. Essa distribuição era esperada porque a pesquisa nesse campo é fortemente vinculada aos programas de pós-graduação senso estrito, mais numerosos e mais antigos na região sudeste que nas demais. Vale ressaltar que, além disso, apenas dois desses programas têm área de concentração em Administração em Enfermagem - um no Sudeste e outro no Nordeste.

Quanto à titulação dos autores, 30 artigos (11\%) não apresentaram esta informação. Do restante, os mestres foram os autores mais frequentes, com 127 (45\%); seguidos pelos doutores, 68 (24\%); especialistas, 40 (14\%); mestrandos, cinco (2\%); doutorandos, dois (1\%); e, somente graduados, 13 (5\%). Chama à atenção a pouca participação de graduados e a ausência de alunos de graduação, nas pesquisas sobre Administração em Enfermagem, o que faz pensar ser esta uma área de interesse de 


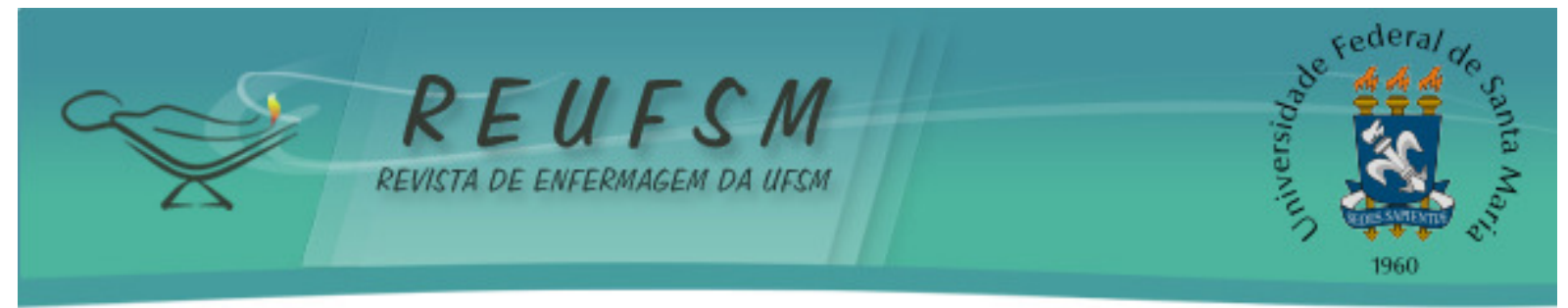

enfermeiros mais maduros e experientes que, já exercendo cargos de direção, preferem se aliar a pesquisadores titulados e/ou que estão na mesma etapa de desenvolvimento, para a realização de pesquisas, ao invés de procurar os mais jovens, talvez mais voltados para as questões assistenciais que para as gerenciais.

Quanto a posição na hierarquia de autoria no artigo, a Tabela 2 aponta que em mais da metade dos artigos, o enfermeiro gestor foi o autor principal.

Tabela 2 - Posição de autoria em artigos de periódicos científicos, de enfermeiros gestores, 20052010.

\begin{tabular}{|c|c|c|}
\hline Posição de Autoria & N. & $\%$ \\
\hline 1 & 130 & 45,6 \\
\hline 2 & 45 & 15,8 \\
\hline 3 & 59 & 20,7 \\
\hline 4 & 30 & 10,5 \\
\hline 5 & 13 & 4,6 \\
\hline 6 & 7 & 2,5 \\
\hline 7 & 1 & 0,4 \\
\hline Total & 285 & 100,0 \\
\hline
\end{tabular}

Esse papel preponderante de protagonista deixa entrever que a pesquisa nesse campo é conduzida principalmente por quem está à frente da administração do serviço, o qual também é o detentor dos meios de acesso às fontes de informação e o provedor de recursos (ou o interlocutor principal de quem o é) para a pesquisa.

Quanto a população dos estudos, foram descritos “Clientes” em 78 artigos, seguida da categoria "Equipe de Enfermagem" em 58, depois pela "Equipe multiprofissional" em 32, "Documentos não acadêmicos" em 25 e "Bases de Dados Acadêmicas" com 15 artigos. Desse modo, pode-se afirmar que o enfermeiro que figurou como autor de textos, nos periódicos estudados, estava vinculado a assistência aos pacientes, a despeito de exercer cargos administrativos, demonstrando a capacidade profissional do enfermeiro de conciliar suas funções na estrutura organizacional com o cuidado da saúde das pessoas e, a essas, acrescer a função de pesquisador.

Esse comportamento já foi detectado em enfermeiros com função dupla de assistência e gerenciamento, que relataram preferência pelo cuidado do paciente como prioridade sobre o processo de trabalho gerencial em enfermagem, principalmente nos aspectos burocráticos. ${ }^{16}$ Além disso, a busca pela harmonia entre gerência e assistência deve ser defendida pelo enfermeiro e valorizada pela instituição na qual trabalha, evitando o desvio do potencial do enfermeiro em relação ao cuidado do paciente. ${ }^{17}$

Após indexação e processamento terminológico dos descritores atribuídos pelos autores, somaram-se 417 termos diferentes, totalizando 858 menções. Coincidiram com o Tesauro do Ministério da Saúde, 205 (49,2\%) termos correspondentes aos descritores originais, com $64,4 \%$ das menções. 0 restante dos descritores foi adaptado ou permaneceu na forma original de apresentação.

A análise dos termos de modo absoluto revelou que os temas foram variados, sendo os mais frequentes "Enfermagem" com 61 menções (7,1\%); "Cuidados de Enfermagem" com 30 (3,5\%); “Diagnóstico de Enfermagem" com 17 (2\%); “Unidade de Terapia Intensiva" com 13 menções (1,5\%); "Recursos Humanos de Enfermagem no Hospital” com 11 (1,3\%); “Família” com dez (1,2\%); “Ensino de Enfermagem” e "Qualidade 


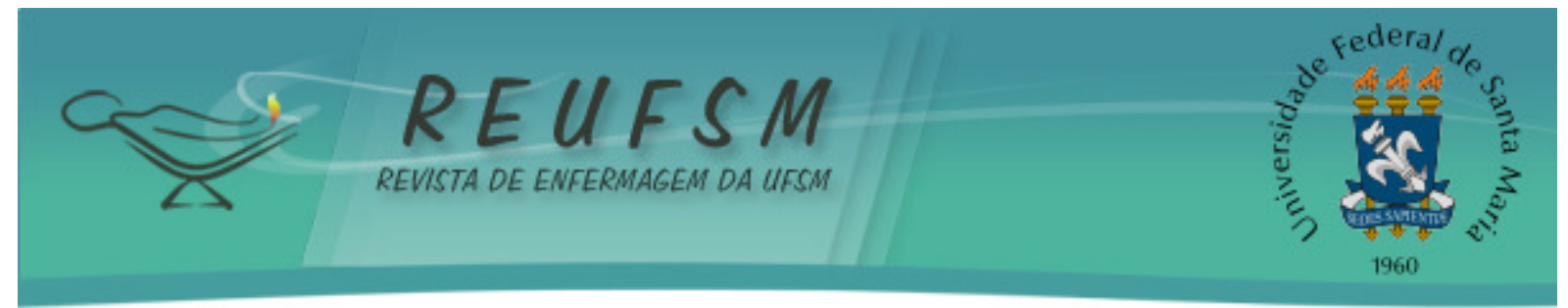

de Enfermagem" com nove (1\%) cada. Naturalmente, os dois primeiros termos indicados já eram esperados, pois se tratam de descritores abrangentes.

Finalmente, foram analisados os termos conforme a Estrutura do Conhecimento sobre Administração em Enfermagem, que reuniu 3,8\% de termos diferentes e 7,1\% de termos citados. ${ }^{9}$ Os resultados, que se referem exclusivamente aos textos que abordavam aspectos gerenciais, podem ser visualizados na Tabela 3.

Tabela 3 - Descritores de artigos de periódicos Qualis A e B produzidos por enfermeiros gestores, 2005-2011, segundo a Estrutura do Conhecimento sobre Administração em Enfermagem. ${ }^{15}$

\begin{tabular}{lrr}
\hline Categoria Temática & N. & $\%$ \\
\hline Prática de Administração de Recursos Humanos (Gestão de Pessoas) & 24 & 39,3 \\
Prática de Administração de Recursos de Informação & 8 & 13,1 \\
Prática de Administração de Recursos Financeiros & 7 & 11,5 \\
Prática de Administração de Recursos Físicos & 7 & 11,5 \\
Métodos de Intervenção & 6 & 9,8 \\
Prática de Administração de Recursos Políticos & 5 & 8,2 \\
Prática de Administração de Recursos Materiais & 3 & 4,9 \\
Bases Ideológicas e Teóricas & 1 & 1,6 \\
\hline Total & 61 & 100 \\
\hline
\end{tabular}

A “Administração de Recursos Humanos" ou a "Gestão de pessoas" foi a prática de gestão mais abordada pelos enfermeiros gestores, com menção de 39,3\% do conjunto dos temas. Esse resultado é condizente com os achados de outro estudo sobre cursos de especialização em Administração em Enfermagem oferecidos em universidade federais, que apresentou $29 \%$ da abordagem curricular centrada na mesma prática. ${ }^{18}$

No presente estudo também se encontrou autores que abordaram outras práticas de gestão tais como Administração de Recursos de Informação com oito $(13,1 \%)$ menções e Administração de Recursos Financeiros e Físicos com sete $(11,5 \%)$. 0 restante dos termos apresentou equilíbrio de frequência, em níveis inferiores a $10 \%$.

É esperado que o interesse do enfermeiro gestor esteja voltado para a investigação no campo da gestão de pessoas porque a força de trabalho em enfermagem sob o seu comando é muito numerosa e estratificada em pelo menos três diferentes categorias profissionais. O enfrentamento do desafio de dimensionar, recrutar, selecionar, contratar, distribuir, avaliar o desempenho, promover o desenvolvimento e supervisionar esse contingente ocupa a maior parte do tempo do enfermeiro gestor e the coloca muitas questões de pesquisa. Isso não quer dizer, no entanto, que o gerenciamento de outros recursos the seja indiferente do ponto de vista da eleição de objetos de estudo, mas apenas que, diante da relativa escassez de conhecimentos disponíveis nesse campo de atuação, a prioridade recaia sobre o aspecto mais desafiador.

\section{CONCLUSÃO}

A presente pesquisa permitiu analisar as publicações na área de enfermagem e, por meio destas, descrever parte do comportamento de pesquisa de enfermeiros que desenvolvem as funções de gestores e pesquisadores. 


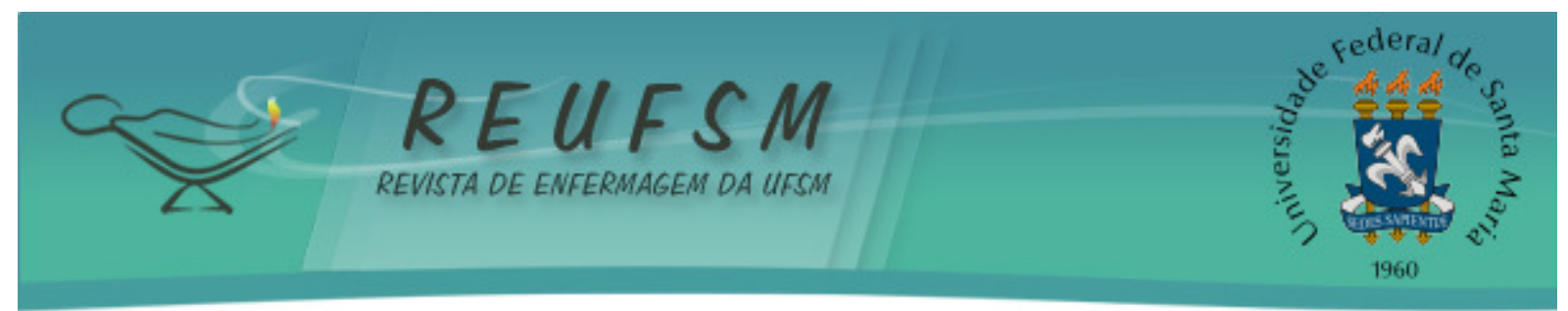

A maioria dos autores se autodenominou chefe ou coordenador de setor, atuante em clínicas médica, cirúrgica e UTI, titulado como mestre e era procedente da Região Sudeste, sendo os principais autores dos textos publicados.

Devido a quantidade de sujeitos de pesquisa concentrar-se em pacientes e familiares, notou-se preferência por objetos de estudo de natureza assistencial. Os termos atribuídos pelos autores foram diversificados, sem apontamento de tendência temática predominante. Quando centrados em questões de pesquisa sobre a atividade administrativa, estes tiveram tendência para o enfoque em gestão de pessoas.

0 estudo abrangeu cinco anos recentes da produção científica sobre o tema e, apesar dessa limitação, pode-se concluir que os enfermeiros gestores têm contribuído para a ampliação do conhecimento tanto no campo assistencial quanto gerencial.

\section{REFERÊNCIAS}

1. Lima JA, Alvarenga D, Bettarello LEL. A enfermagem desencadeando o processo de mudança organizacional. Rev Adm Saúde [Internet]. 2001 jan/mar [acesso em 2012 nov 21];3(10):17-20. Disponível em: http://www.cqh.org.br/files/ARTIGORAS10.pdf.

2. Lopes CM. Aplicação de resultados de pesquisas na prática da enfermagem. São Paulo (SP): Sarvier; 1993.

3. Kurcgant $P$, Ciampone MHT. A pesquisa na área de gerenciamento em enfermagem no Brasil. Rev Bras Enferm [Internet]. 2005 mar-abr [acesso em 2012 nov 21];58(2):161-4. Disponível em: http://www.scielo.br/scielo.php?script=sci_arttext\&pid=S0034$71672005000200006 \& \operatorname{lng}=p t \& n r m=$ iso\&tlng=pt.

4. Ciampone MHT, Felli VEA, Castilho V, Kurcgant $P$. A produção do conhecimento na área de administração de serviços de enfermagem do programa de pós-graduação. Rev Esc Enferm USP [Internet]. 2005 [acesso em 2012 nov 21];39(Esp.):535-43. Disponível em: http://www.scielo.br/pdf/reeusp/v39nspe/v39nspea05.pdf.

5. Contim D, Sanna MC. Ensino de administração de serviços de saúde: perfil de enfermeiras que exerceram a docência. Acta Paul Enferm [Internet]. 2011[acesso em 2013 abr 20];24(6):756-61. Disponível em: http://www.scielo.br/scielo.php?pid=S010321002011000600004 \&script=sci_arttext.

6. Macias-Chapula CA. O papel da informetria e da cienciometria e sua perspectiva nacional e internacional. Ci Inf [Internet]. 1998 maio/ago [acesso em 2013 abr 20];(27)2:134-40.

http: / /www.scielo.br/scielo.php?script=sci_arttext\&pid=S0100-

$19651998000200005 \&$ lng=en\&nrm=iso\&tlng=pt.

7. Coordenação de Aperfeiçoamento de Pessoal de Nível Superior [CAPES]. Brasília, DF: Ministério da Educação [Internet]. [acesso em 2012 nov 21]. Disponível em: http: / /qualis.capes.gov.br/webqualis/principal.seam

8. Ruthes RM, Cunha ICKO. Os desafios da administração hospitalar na atualidade. Rev Adm Saúde [Internet]. 2007 jul-set [acesso em 2012 nov 21];9(36):93-102. Disponível em: http: / /www.cqh.org.br/files/RAS36\%20-\%20os\%20desafios.pdf.

9. Bufrem L, Prates Y. O saber científico registrado e as práticas de mensuração da informação. Ci Inf [Internet]. 2005 maio-ago [acesso em 2013 abr 20];34(2):9-25. Disponível em: http://www.scielo.br/pdf/ci/v34n2/28551. 


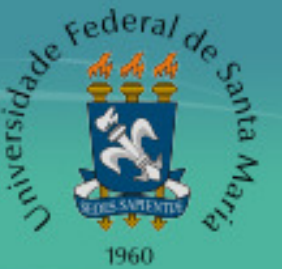

10. Merighi MAB, Gonçalves R, Ferreira FC. Estudo bibliométrico sobre dissertacõos e teses em enfermagem com abordagem fenomenológica: tendências e perspectivas. Rev Latinoam Enferm [Internet]. 2007 jul-ago [acesso em 2013 abr 20];15(4):645-50. Disponível em: http: / /www.scielo.br/scielo.php?script=sci_arttext\&pid=S0104-

$11692007000400019 \& \operatorname{lng}=e n \& n r m=$ iso\&tlng=pt.

11. Rosa LM, Silva AMF, Pereima RSMR, Santos SMA, Meirelles BHS. Família, cultura e práticas de saúde: um estudo bibliométrico. Rev Enferm UERJ [Internet]. 2009 out-dez [acesso em 2013 abr 20];17(4):516-20. Disponível em: http://www.facenf.uerj.br/v17n4/v17n4a11.pdf

12. Vaz DC, Silva CRL, Figueiredo NMA. A utilização da bibliometria na análise do referente conforto. Cogitare Enferm [Internet]. 2010 out-dez [acesso em 2013 abr 20];15(4):736-41. Disponível

em: http://ojs.c3sl.ufpr.br/ojs2/index.php/cogitare/article/viewArticle/20378.

13. Wunsch S, Budó MLD, Garcia RP, Oliveira SG, Gewehr M, Scimith MD, et al. População rural e enfermagem: uma revisão bibliométrica. Rev Enferm UFSM [Internet]. 2012 set-dez [acesso em 2013 abr 20];2(3):539-46. Disponível em: http://cascavel.ufsm.br/revistas/ojs2.2.2/index.php/reufsm/article/view/3656.

14. Brasil. Ministério da Saúde. Biblioteca Virtual em Saúde. Tesauro do Ministério da Saúde: versão preliminar, atualizada em 02/02/2009 [Internet]. Brasília (DF): Ministério da Saúde. [acesso em 2012 nov 21]. Disponível em: http://bvsms.saude.gov.br/bvs/publicacoes/tesauro_ms.pdf.

15. Sanna MC. A estrutura do conhecimento sobre administração em enfermagem. Rev Bras Enferm [Internet]. 2007 maio-jun [acesso em 2012 nov 21];60(3):336-8. Disponível em: http://www.scielo.br/scielo.php?script=sci_arttext\&pid=S0034-71672007000300017.

16. Giordani JN, Bisogno SBC, Silva LAA. Percepção dos enfermeiros frente às atividades gerenciais na assistência ao usuário. Acta Paul Enferm [Internet]. 2012 [acesso em 2013 abr 20];25(4):511-6. Disponível http: / /www.scielo.br/scielo.php?script=sci_arttext\&pid=S0103$21002012000400005 \&$ lng=pt\&nrm=iso\&tlng=pt.

17. Silvino ZR, Jesus DL, Christovam BP, Souza DF, Alves EMC. The performance of nurses in the practice of managing in hospitals: a integrative review. Rev Pesqui Cuid Fundam [Internet]. 2011 jul-set [acesso em 2013 abr 20];3(3):2233-43. Disponível em: http://www.seer.unirio.br/index.php/cuidadofundamental/article/viewArticle/1353.

18. Meneses AS, Sanna MC. Acessibilidade e conteúdo de informação eletrônica sobre cursos de especialização em administração em enfermagem. Rev Esc Enferm USP [Internet]. $2011 \mathrm{abr}$ [acesso em 2012 nov 21];45(2):356-62. Disponível em: http: / / www.scielo.br/scielo.php?pid=S0080-62342011000200008\&script=sci_arttext.

Data de recebimento: $21 / 11 / 2012$

Data de aceite: 13/05/2013

Contato com autor responsável: Ricardo Quintão Vieira

Endereço: Rua Ernesto Barreto, n.30, casa 02, Jardim Cliper, São Paulo, SP

CEP: 04827-183

E-mail: ricqv@ig.com.br 